\title{
Hemşirelik Öğrencilerinde Menstruasyon Tutumunun Genital Hijyen Davranışlarına Etkisi
}

\section{The Effect of Menstrual Attitude on Genital Hygiene Behaviors of Nursing Students}

\author{
Ruken Yağız Altıntaşs ${ }^{1}$, Sümeyye Bakır*², Irem Gül ${ }^{3}$, Necla Süer ${ }^{4}$, Oya Kavlak
}

\begin{abstract}
Aim: This study aimed to determine the effect of the menstrual attitudes of female nursing students on their genital hygiene behaviors. Methods: The cross-sectional study was conducted with 341 female student in the 2019-2020 academic year. The data were collected by "Personal Information Form", "Genital Hygiene Behavior Scale" and "Menstruation Attitude Scale". Descriptive statistics, OneWayAnova test, correlation and regression analysis methods were used in analyzing the data. Results: In this study 78,9 of the respondents were 20 years and above, $39,9 \%$ of them were in the first class. Most of them $(64,5 \%)$ were lived in the dormitory. It was determined that the mean

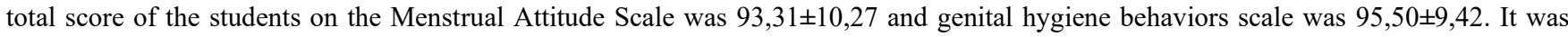
found that there is a positive relationship between the perception of menstruation as a natural phenomenon and genital hygiene behaviors and menstrual hygiene. As a result of the regression analysis, it was found that the number of pads used was effective on general hygiene behavior and awareness of abnormal findings, while the length of menstruation and the number of pads were effective on menstrual hygiene. Conclusion: It was found that students' perception of menstruation as a natural phenomen on positively affected their menstrual hygiene behavior. Accordingly, it is thought that positive attitudes about menstruation from the first experience will positively affect the general health status of women in all life periods.
\end{abstract}

Key words: Genital hygiene, menstruation, student, attitude

\section{ÖZET}

Amaç: Bu araştırma hemşirelik bölümünde okuyan kız öğrencilerin menstruasyon tutumlarının genital hijyen davranışları üzerine etkisini belirlemek amacıyla yapılmıştır. Yöntem: Kesitsel türde yapılan araştırmaya, 2019-2020 eğitim yılında olan 341 öğrenci katılmıştır. Veriler kişisel bilgi formu, Genital Hijyen Davranışları Ölçeği ve Menstruasyon Tutum Ölçeği ile toplanmıştır. Verilerin analizinde tanımlayıcı istatistikler, OneWayAnova testi, korelasyon ve regresyon analiz yöntemleri kullanılmıştır. Bulgular: Araştırmaya katılan öğrencilerin \%78,9'u 20 yaş ve üstünde, \%39,9'u birinci sınıfta ve \%64,5'i yurtta yaşamaktadır. Öğrencilerin Menstrual Tutum Ölçeği toplam puanı

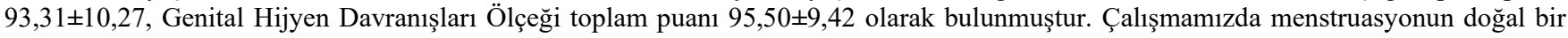
olgu olarak görülmesi ile genital hijyen davranışları ve adet hijyeni arasında olumlu ilişki olduğu saptanmıștır. Regresyon analizi sonucunda kullanılan ped sayısının genel hijyen davranışı ve anormal bulgu farkındalığı üzerinde etkili olduğu, menstruasyon uzunluğu ve ped sayısının ise adet hijyeni üzerinde etkili olduğu bulunmuştur. Sonuç: Öğrencilerin menstruasyonu doğal bir olgu olarak görmesinin adet hijyeni davranışlarını olumlu etkilediği bulunmuştur. Bu doğrultuda ilk deneyimden itibaren menstruasyonla ilgili kazandırılacak olumlu tutumların, kadınların tüm hayat dönemlerinde genel sağlık durumunu olumlu yönde etkileyeceği düşünülmektedir.

Anahtar kelimeler: Genital hijyen, menstruasyon, öğrenci, tutum

Received / Geliş tarihi: 02.05.2021, Accepted / Kabul tarihi: 10.07.2021

${ }^{1}$ Ege Üniversitesi Hemşirelik Fakültesi, İZMİR (ORCID: 0000-0001-7299-8349)

${ }^{2}$ Ege Üniversitesi Hemşirelik Fakültesi, İZMIR (ORCID: 0000-0003-3141-9042)

${ }^{3}$ Ege Üniversitesi Hemşirelik Fakültesi, İZMIR (ORCID: 0000-0002-9391-2409)

${ }^{4}$ Ege Üniversitesi Tıp Fakültesi, Hemşire, IZMIR (ORCID: 0000-0001-5849-7062)

${ }^{5}$ Ege Üniversitesi Hemşirelik Fakültesi, İZMİR (ORCID: 0000-0003-3242-5313)

*Address for Correspondence / Yazş̧ma Adresi: Ege Üniversitesi Hemşirelik Fakültesi, İzmir -TÜRKIYE, E-mail: sumeyyebakir35@gmail.com Tel: +902323115540 / +905312081697

Altıntaş RY, Bakır S, Gül İ, Süer N, Kavlak O. Hemşirelik Öğrencilerinde Menstruasyon Tutumunun Genital Hijyen Davranışlarına Etkisi. TJFMPC, 2021;15(3): 568-575.

DOI: $10.21763 /$ tjfmpc.931262 


\section{GiRiș}

Üreme çağının simgesi olan menarş, doğal bir süreçtir ve dünya popülasyonunun yarısı bu süreci yaşamaktadır. ${ }^{1,2}$ Menstruasyon, sosyal ve kültürel özelliklere bağlı olarak her toplumda farklı bir şekilde algılanmakta ve yaşanmaktadır. ${ }^{3}$ Geçmişten günümüze kadar birçok farklı toplumda doğa üstü bir olay, patolojik bir durum veya menstruasyon döneminde kadınların günlük rutin ișleri yapmamasını gerektiren olumsuz bir durum olarak düşünülmüştür. ${ }^{4}$ Türk toplumunda ise menstruasyon genel olarak "kirlenmek" ya da "hastalanmak" olarak isimlendirilmektedir. ${ }^{5}$ Kadınların menstruasyona ilişkin tutumlarını bireysel bilgiler, yaş, deneyimler, mitler, gelenekler, sosyal öğrenme ve kültürel inançlar vb. etkilemektedir. ${ }^{6}$ Ülkemizde 586 kadın ile yapılan bir çalıșmada, kadınların $\% 64,2$ 'si menstruasyonu olumsuz bir deneyim olarak tanımlamıştır. ${ }^{7}$ 14-17 yaş grubundaki kız öğrenciler ile yapılan bir çalışmada, ilk menstrual deneyimini olumsuz olarak değerlendiren kızların büyük çoğunluğunun menstruasyona ilişkin sonraki görüşlerinin de olumsuz olduğu, daha önce menarşa ilişkin bilgi alan kızların ilk deneyim ve sonraki tutumlarının olumlu olduğu bulunmuştur. ${ }^{8} 34$ farklı ülkeden 53 kadın ile yapılan odak grup görüşmelerinde ilk menstruasyon deneyiminde annenin verdiği tepkinin önemli olduğu ve kültürel ve dini faktörlerin kadınların menarş reaksiyonlarında etkili olduğu saptanmıştır. ${ }^{9}$

Kültürel olarak menstruasyonun "hijyenik bir kriz" olarak görülmesi eğilimi, kirli bir durum algısını desteklese de hijyenik uygulamaların artırılması bir çözüm yolu olarak görülmüştür. ${ }^{10}$ Hennegan ve ark. yaptıkları meta analizde, düşük ve orta gelirli ülkelerdeki kadınların menstrual deneyimlerinin fiziksel ve psikolojik sağlıklarını etkilediğini belirtmişlerdir. ${ }^{11}$ Torondel ve ark. yaptıkları çalışmada, yetersiz menstrual hijyen uygulamaları ile bakteriyel vajinozis ve kandida gibi enfeksiyonlar arasında güçlü ilişki olduğu bulunmuştur. ${ }^{12}$ Uskul yaptığı çalışmada, kadınların büyük çoğunluğunun menstruasyonun üreme ve cinsellik için ne anlama geldiğini öğrenmek yerine öncelikle hijyenik menstrual ürünleri nasil kullanacaklarını ve yöneteceklerini öğrenmekle uğraştıklarını belirtmiştir. ${ }^{9}$ Literatürde öğrenciler ile yapılan çalışmalar genital hijyen uygulamaları ve genital hijyen davranışları düzeyi üzerine odaklanmaktadır. ${ }^{13-15} \mathrm{Bu}$ doğrultuda çalışmamızda hemşirelik bölümünde okuyan kız öğrencilerin menstruasyon tutumlarının genital hijyen davranışları üzerine etkisi olup olmadığının araştııılması amaçlanmaktadır.

\section{YÖNTEM}

\section{Örneklem}

Araştırma kesitsel türde bir araştırma olup evrenini, 2019-2020 eğitim öğretim yılı mart ayında Ege Üniversitesi Hemşirelik Fakültesi'nde kayıtlı olup öğrenimine devam eden hazırlık sınıfı hariç $1,2,3$. ve 4 . sinıfta olan kız öğrenciler $(\mathrm{N}=1220)$ oluşturmuştur. Örneklem seçimi tabakalı rastgele örneklem yöntemi ile yapılmış ve $\% 99$ güven aralığında evreni bilinen örneklem formülü ile belirlenmiștir. Daha sonra örneklemde her tabakadan (1.,2.,3. ve 4. sinıf öğrencileri) kaç öğrenci yer alacağı hesaplanmış ve 376 öğrenciye ulaşılması hedeflenmiştir. Çalışma konusunun katılımcıların kişisel mahremiyetine yönelik sorular içermesi nedeni ile bazı katılımcılar çalışmaya katılmayı reddetmiş̧ir. Çalışmaya katılmayı 346 öğrenci kabul etmiştir. Kontrol aşamasında beş anket formunda eksiklikler olduğu için çıkarılmıştır. Çalışma 341 veri ile tamamlanmıştır.

\section{Veri Toplama Araçları}

Veriler yüz yüze görüşme yöntemi ile toplanmıştır.

Kişisel Bilgi Formu: Araştırmacılar tarafından hazırlanan formda öğrencilerin; sosyodemografik özellikleri ve menstruasyon özelliklerini sorgulayan 8 soru yer almaktadır.

Genital Hijyen Davranışları Ölçeği (GHD-Ö): Karahan tarafından geliştirilen ölçek, toplam 23 madde ve üç alt boyuttan oluşmaktadır. Ölçekten 23-115 arası puan alınmakta olup, yüksek puanlar genital hijyen davranışının olumlu olduğunu göstermektedir. Ölçeğin cronbach alfa değeri 0,80 olarak saptanmıştır. ${ }^{16}$ Çalışmamızda ölçeğin cronbach alfa değeri 0,81 olarak bulunmuştur.

Menstruasyon Tutum Ölçeği (MTÖ): Kulakaç ve ark. tarafından Türkçe geçerlilik ve güvenilirliği yapılan ölçeğin 33 maddesi ve 5 alt boyutu bulunmaktadır. Ölçek likert tiptedir (1-7 puan). ${ }^{17}$ MTÖ'den alınan puanların yüksek olması, menstruasyon tutumunun "olumlu" olduğunu göstermektedir. Çalışmamızda ölçeğin cronbach alfası 0,70 olarak bulunmuştur.

\section{İstatistiksel Analiz}

Verilerin değerlendirilmesinde SPSS 23.0 paket programı kullanılmıştır. Daha sonra verilerin normal dağılıma uygunluğu araştırılmıştır. Tanımlayıcı istatistiklerden sayısal değişkenler için ortalama, standart sapma, minimum, maksimum; kategorik değişkenler için sayı ve yüzde verilmiştir. Bağımsız iki grup arasında 
sayısal değişkenlerin karşılaştırmalarında normal dağılım sağlandığı için bağımsız t testi, ikiden fazla grupta ise OneWayAnova testi uygulanmıştır. Ölçekler arasındaki ilişki için Pearson Korelasyon analizi ve ilişki saptanan parametreler için regresyon analizi yapılmıştır.

\section{Etik Hususlar}

Araştırmanın yapılabilmesi için Ege Üniversitesi Sağlık Bilimleri Bilimsel Araştırma ve Yayın Etiği Kurulu'ndan 27.02.2020 tarihli 02/08 karar sayilı 551 nolu protokol ile etik kurul izni alınmıştır. Öğrencilere anketi yanıtlamadan önce bilgilendirilmiş onam formu ile yazılı ve sözlü açıklama yapılmıştır. Onam belgesinde çalışmanın amacı, yöntemi, hedefleri ve olası tehlikeleri, bireylerin araştırmaya katılma ya da ayrılma konusunda tamamen serbest oldukları açıklanmıştır.

\section{BULGULAR}

\section{Sosyo-demografik ve Menstruasyona İliş̧in Özellikler}

Çalışma 341 öğrenci ile tamamlanmıştır. Araştırmaya katılan öğrencilerin \% 78,9'u 20 yaş ve üstündedir ve \% 39,9'u birinci sinıfta okumaktadır. Ailesinin gelir durumunu gelir gidere denk olanlar öğrencilerin \%75,1'ini oluşturmaktadır. Öğrencilerin büyük çoğunluğu yurtta yaşamaktadır. Çalışmamıza katılan öğrencilerin ortalama menstruasyon sıklığ 1 (gün) 29,41 $\pm 6,68$, menstruasyon süresi (gün)

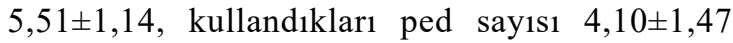
olarak belirlenmiştir (Tablo 1).

Tablo 1. Araştırmaya katılan öğrencilerin sosyo-demografik özelliklerine göre dağılımı

\begin{tabular}{|c|c|c|}
\hline Değişkenler & Sayı (n) & $\%$ \\
\hline \multicolumn{3}{|l|}{ Yaş } \\
\hline 19 yaş ve altı & 72 & 21,1 \\
\hline 20 yaş ve üstü & 269 & 78,9 \\
\hline \multicolumn{3}{|l|}{ Sinif } \\
\hline 1. sinif & 136 & 39,9 \\
\hline 2. sinif & 78 & 22,9 \\
\hline 3. sinif & 61 & 17,9 \\
\hline 4. sinif & 66 & 19,3 \\
\hline \multicolumn{3}{|l|}{ Ailenin Gelir Durumu } \\
\hline Gelir giderden $\mathbf{a z}$ & 55 & 16,1 \\
\hline Gelir gidere denk & 256 & 75,1 \\
\hline Gelir giderden fazla & 30 & 8,8 \\
\hline \multicolumn{3}{|l|}{ En uzun yaşadığ 1 yer } \\
\hline Büyükşehir & 105 & 30,8 \\
\hline III & 42 & 12,3 \\
\hline İlçe & 141 & 41,3 \\
\hline Köy & 53 & 15,6 \\
\hline \multicolumn{3}{|l|}{ Birlikte Yaşadığı Kişiler } \\
\hline Aile & 83 & 24,3 \\
\hline Yurt & 220 & 64,5 \\
\hline Arkadaş & 26 & 7,6 \\
\hline Diğer & 12 & 3,6 \\
\hline \multirow[t]{2}{*}{ Toplam } & 341 & 100 \\
\hline & \multicolumn{2}{|c|}{ ( X \pm SS Min-Max) } \\
\hline \multicolumn{2}{|l|}{ Ortalama Menstruasyon Sıklığı (gün) } & $29,41 \pm 6.68 \quad(2-90)$ \\
\hline \multicolumn{2}{|l|}{ Menstruasyon Süresi (gün) } & $5,51 \pm 1,14(2-10)$ \\
\hline \multicolumn{2}{|l|}{ Kullanılan Ped Sayısı (adet) } & $4,10 \pm 1,47(1-11)$ \\
\hline
\end{tabular}

\section{Menstruasyon Tutumu ve Genital Hijyen Davranışlarına İlişkin Özellikler}

Çalışmaya katılan öğrencilerin ölçek toplam ve alt boyut puan ortalamaları tablo 2'de yer almaktadır. MTÖ toplam puan ortalaması

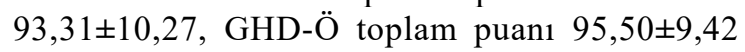

olarak bulunmuştur. Ölçekler arasında yapılan Pearson Korelasyon analizinde MTÖ doğal bir olgu boyutu ile ve GHD-Ö ve Adet Hijyeni (AH) alt boyutu arasında istatistiksel olarak anlamlı pozitif yönde zayıf bir ilişki bulunmuştur $(\mathrm{r}=0,116, \mathrm{p}=0,032 ; \mathrm{r}=0,137, \mathrm{p}=0,011)$. 
Tablo 2. Araştırmaya katılan öğrencilerin Genital Hijyen Davranışları ve Menstruasyon Tutum Ölçeği toplam ve alt boyut puan ortalamalarına ilişkin bulgular

\begin{tabular}{|c|c|c|}
\hline Ölçek ve Boyutları & Min-Maks & $\mathbf{X} \pm \mathbf{S S}$ \\
\hline Genel Hijyen & $33,00-66,00$ & $49,36 \pm 5,01$ \\
\hline Menstrual Hijyen & $21,00-40,00$ & $34,45 \pm 3,92$ \\
\hline Anormal Bulgu farkındalığı & $4,00-15,00$ & $11,68 \pm 2,37$ \\
\hline Genital Hijyen Davranışları Ölçeği & $68,00-115,0$ & $95,50 \pm 9,42$ \\
\hline Güçsüz bırakan bir olgu & $17,00-51,00$ & $33,00 \pm 6,10$ \\
\hline Rahatsız edici bir olgu & $8,00-29,00$ & $17,38 \pm 3,94$ \\
\hline Doğal bir olgu & $10,00-25,00$ & $18,99 \pm 2,89$ \\
\hline Fark etme/sezinleme & $5,00-20,00$ & $10,31 \pm 2,85$ \\
\hline Menstruasyonun etkilerini inkar & $11,00-28,00$ & $19,39 \pm 2,75$ \\
\hline Menstruasyon Tutum Ölçeği & $64,00-119,0$ & $93,31 \pm 10,27$ \\
\hline
\end{tabular}

Araştırmaya katılan öğrencilerin sosyodemografik özelliklerinden okumakta olduğu sinıf ve GHD-Ö toplam ve alt boyutları arasında istatistiksel olarak anlamlı fark bulunmuştur $(p<0,05)$. GHD-Ö ve AH alt boyutu ile ailenin gelir durumu arasinda istatistiksel olarak anlamlı fark saptanmıştır $(\mathrm{p}<0,05)$ (Tablo 3). Öğrencilerin okuduğu sınıf değișkeni ile MTÖ Rahatsiz Edici Bir Olgu ve Menstruasyonun
Olacağını Önceden Fark Etme/Sezinleme alt boyutları arasında istatistiksel olarak anlamlı fark bulunmuştur $(\mathrm{p}<0,05)$. MTÖ Güçsüz Bırakan Bir Olgu ve ailenin gelir durumu arasında istatistiksel olarak anlamlı fark bulunmuştur $(\mathrm{p}<0,05)$. MTÖ Menstruasyonun Olacağını Önceden Fark Etme/Sezinleme alt boyutu ve birlikte yaşanılan kişiler değişkeni arasında istatistiksel olarak anlamlı fark bulunmuștur $(\mathrm{p}<0,05)$ (Tablo 4).

Tablo 3. Araştırmaya katılan öğrencilerin sosyo-demografik özellikleri ile genital hijyen davranışları ölçeği toplam ve alt boyut puan ortalamalarının karşılaştırılması

\begin{tabular}{|c|c|c|c|c|c|c|}
\hline & \multicolumn{2}{|c|}{ Değişkenler } & Min-Maks & $\mathbf{X} \pm \mathrm{SS}$ & Test & $\mathbf{p}$ \\
\hline \multirow{7}{*}{$\begin{array}{l}\text { Genital Hijyen } \\
\text { Davranışları } \\
\text { Ölçeği }\end{array}$} & \multirow{4}{*}{ Sinıf } & 1. sinif & $68,00-114,00$ & $93,76 \pm 8,99$ & \multirow{4}{*}{$12,58 *$} & \multirow{4}{*}{$0,00 * *$} \\
\hline & & 2. $\sin I f$ & $70,00-115,00$ & $93,28 \pm 9,92$ & & \\
\hline & & 3. sinif & $77,00-113,00$ & $95,95 \pm 8,52$ & & \\
\hline & & 4. sinif & $80,00-115,00$ & $101,31 \pm 8,11$ & & \\
\hline & & Gelir giderden az & $75,00-112,00$ & $92,61 \pm 9,60$ & & \\
\hline & Gelir & Gelir gidere denk & $68,00-115,00$ & $95,92 \pm 9,39$ & $3,40 *$ & $0,03 * *$ \\
\hline & & $\begin{array}{c}\text { Gelir giderden } \\
\text { fazla }\end{array}$ & $82,00-109,00$ & $97,26 \pm 8,54$ & & \\
\hline & & 1. sinıf & $33,00-60,00$ & $48,52 \pm 4,89$ & & \\
\hline & & 2. sinif & $38,00-60,00$ & $48,16 \pm 5,18$ & & \\
\hline Boyutu & Sinıf & 3. sinıf & $39,00-59,00$ & $49,57 \pm 4,79$ & & \\
\hline
\end{tabular}




\begin{tabular}{|c|c|c|c|c|c|c|}
\hline & & 4. sinif & $40,00-60,00$ & $52,30 \pm 4,05$ & & \\
\hline \multirow{8}{*}{$\begin{array}{l}\text { Menstrual } \\
\text { Hijyen Boyutu }\end{array}$} & \multirow{5}{*}{ Sinıf } & 1. sinif & $21,00-40,00$ & $33,94 \pm 3,75$ & \multirow{5}{*}{$7,29 *$} & \multirow{5}{*}{$0,00 * *$} \\
\hline & & 2. sinif & $23,00-40,00$ & $33,70 \pm 4,31$ & & \\
\hline & & & $26,00-40,00$ & $34,49 \pm 3,49$ & & \\
\hline & & 3. sinıf & & & & \\
\hline & & 4. sinıf & $26,00-40,00$ & $36,36 \pm 3,62$ & & \\
\hline & \multirow{3}{*}{$\begin{array}{c}\text { Gelir } \\
\text { Durumu }\end{array}$} & Gelir giderden az & $21,00-40,00$ & $33,30 \pm 4,51$ & \multirow{3}{*}{$3,07 *$} & \multirow{3}{*}{$0,048 * *$} \\
\hline & & Gelir gidere denk & $25,00-40,00$ & $34,62 \pm 3,73$ & & \\
\hline & & $\begin{array}{c}\text { Gelir giderden } \\
\text { fazla }\end{array}$ & $23,00-40,00$ & $35,13 \pm 4,12$ & & \\
\hline \multirow{4}{*}{$\begin{array}{l}\text { Anormal } \\
\text { Bulgu } \\
\text { Farkındalığı } \\
\text { Boyutu }\end{array}$} & \multirow{4}{*}{ Sinıf } & 1. Sinıf & $5,00-15,00$ & $11,29 \pm 2,35$ & \multirow{4}{*}{$5,60 *$} & \multirow{4}{*}{$0,01 * *$} \\
\hline & & 2. sinif & $4,00-15,00$ & $11,41 \pm 2,51$ & & \\
\hline & & 3. sinif & $7,00-15,00$ & $11,88 \pm 2,00$ & & \\
\hline & & 4. sinif & $6,00-15,00$ & $12,65 \pm 2,29$ & & \\
\hline
\end{tabular}

Tablo 4. Araştırmaya katılan öğrencilerin sosyo-demografik özellikleri ile Menstrual Tutum Ölçeği Toplam ve Alt Boyut Puan Ortalamalarının Karşılaştırılması

\begin{tabular}{|c|c|c|c|c|c|c|}
\hline & Değişk & & Min-Maks & $\mathbf{X} \pm \mathbf{S S}$ & Test Değeri & $\mathbf{p}$ \\
\hline \multirow{4}{*}{$\begin{array}{l}\text { Rahatsiz } \\
\text { edici bir } \\
\text { olgu boyutu }\end{array}$} & \multirow{4}{*}{ Sinıf } & 1. sinif & $8,00-29,00$ & $16,46 \pm 3,86$ & \multirow{4}{*}{$4,82 *$} & \multirow{4}{*}{$0,03 * *$} \\
\hline & & 2. sinif & $8,00-27,00$ & $17,60 \pm 4,05$ & & \\
\hline & & 3. sinif & $10,00-27,00$ & $18,44 \pm 3,77$ & & \\
\hline & & 4. sinif & $11,00-27,00$ & $18,06 \pm 3,79$ & & \\
\hline \multirow{8}{*}{$\begin{array}{l}\text { Fark } \\
\text { etme/sezinl } \\
\text { eme boyutu }\end{array}$} & \multirow{4}{*}{ Sinıf } & 1. sinif & $5,00-20,00$ & $10,86 \pm 3,09$ & \multirow{4}{*}{$3,19 *$} & \multirow{4}{*}{$0,24 *$} \\
\hline & & 2. sinif & $5,00-17,00$ & $9,94 \pm 2,77$ & & \\
\hline & & 3. sinıf & $6,00-18,00$ & $10,21 \pm 2,62$ & & \\
\hline & & 4. sinif & $5,00-17,00$ & $9,71 \pm 2,46$ & & \\
\hline & \multirow{4}{*}{$\begin{array}{c}\text { Birlikte Yaşadığı } \\
\text { Kişiler }\end{array}$} & Aile & $5,00-20,00$ & $10,79 \pm 2,94$ & \multirow{4}{*}{$3,80 *$} & \multirow{4}{*}{$0,10 *$} \\
\hline & & Yurt & $5,00-18,00$ & $10,33 \pm 2,84$ & & \\
\hline & & Arkadaş & $5,00-13,00$ & $8,65 \pm 2,24$ & & \\
\hline & & Diğer & $6,00-16,00$ & $10,33 \pm 2,64$ & & \\
\hline
\end{tabular}

* OneWayAnova Testi

$* * p<0,05$ 

Menstruasyon Tutumunun Genital Hijyen
Davranıșları Üzerine Etkisine Ait Özellikler

Menstruasyon özelliklerinin genital hijyen davranışlarının genel hijyen alışkanlıkları ve adet hijyeni boyutu üzerindeki etkisini araştırmak üzere yapılan basit regresyon analizinde kurulan modelin istatistiksel olarak anlamlı olduğu bulunmuştur $(\mathrm{F}=3,543, \mathrm{p}<0,05 ; \mathrm{F}=9,544 ; \mathrm{p}<0,05)$. Kullanilan ped sayısının, genital hijyen davranışlarının genel hijyen alışkanlıkları ve adet hijyeni boyutu üzerinde istatistiksel olarak anlamlı bir etkisinin olduğu belirlenmiştir ( $\mathrm{t}=3.066, \mathrm{p}<0,05 ; \mathrm{t}=4,757, \mathrm{p}<0,05)$. Menstruasyon özelliklerinin genital hijyen davranışları üzerindeki etkisini araştırmak üzere yapılan basit regresyon analizinde kurulan modelin istatistiksel olarak anlamlı olduğu bulunmuştur $(F=7,307 ; p<0,05)$. Kullanılan ped sayısının, genital hijyen davranışları üzerinde istatistiksel olarak anlamlı bir etkisinin olduğu belirlenmiştir $(t=4,310$, $\mathrm{p}<0,05)$. Menstruasyon özelliklerinin genital hijyen davranışlarının anormal bulgu farkındalığ boyutu üzerindeki etkisini araştırmak üzere de basit regresyon analizi yapılmıştır. Yapılan regresyon analiz sonucuna göre, kurulan modelin istatistiksel olarak anlamlı olduğu bulunmuştur $(\mathrm{F}=3,448 ; \mathrm{p}<0,05)$. Kullanılan ped sayısının, genital hijyen davranışlarının anormal bulgu farkındalığı boyutu üzerinde istatistiksel olarak anlamlı bir etkisinin olduğu görülmektedir $(\mathrm{t}=2,809, \mathrm{p}<0,05)$ (Tablo 5).

Tablo 5. Menstruasyon özelliklerinin genital hijyen davranışları ve menstruasyon durumu üzerindeki etkisinin regresyon analizi sonuçları

\begin{tabular}{|c|c|c|c|c|c|c|c|c|c|}
\hline $\begin{array}{c}\text { Bağımlı } \\
\text { Değișken }\end{array}$ & $\begin{array}{l}\text { Bağımsız } \\
\text { Değișken }\end{array}$ & B & SH & Beta & $\mathbf{t}$ & $\mathbf{p}$ & $\mathbf{F}$ & $\begin{array}{l}\text { Model } \\
\text { (p) }\end{array}$ & $\begin{array}{c}\text { Adjusted } \\
\text { R2 }\end{array}$ \\
\hline \multirow{4}{*}{$\begin{array}{l}\text { Genel } \\
\text { Hijyen }\end{array}$} & Sabit & 48,002 & 2,051 & - & 23,404 & 0,000 & \multirow[t]{4}{*}{3,543} & \multirow[t]{4}{*}{$0,015^{*}$} & \multirow[t]{4}{*}{0,022} \\
\hline & $\begin{array}{l}\text { Ortalama } \\
\text { siklus uzunluğu }\end{array}$ & 0,026 & 0,046 & 0,031 & 0,573 & 0,579 & & & \\
\hline & $\begin{array}{l}\text { Menstruasyon } \\
\text { uzunluğu }\end{array}$ & $-0,352$ & 0,216 & $\begin{array}{c}- \\
0,072 \\
\end{array}$ & $-1,348$ & 0,179 & & & \\
\hline & $\begin{array}{l}\text { Kullanılan ped } \\
\text { sayısı }\end{array}$ & 0,612 & 0,199 & 0,164 & 3,066 & $0,002 *$ & & & \\
\hline $\begin{array}{c}\text { Bağımlı } \\
\text { Değişken }\end{array}$ & $\begin{array}{l}\text { Bağımsız } \\
\text { Değișken }\end{array}$ & B & SH & Beta & $\mathbf{t}$ & $\mathbf{p}$ & $\mathbf{F}$ & $\begin{array}{l}\text { Model } \\
\text { (p) }\end{array}$ & $\begin{array}{c}\text { Adjusted } \\
\text { R2 }\end{array}$ \\
\hline \multirow{4}{*}{$\begin{array}{l}\text { Menstrual } \\
\text { Hijyeni }\end{array}$} & Sabit & 32,773 & 1,430 & - & 22,926 & 0,000 & \multirow[t]{4}{*}{9,544} & \multirow[t]{4}{*}{$0,000 *$} & \multirow[t]{4}{*}{0,069} \\
\hline & $\begin{array}{l}\text { Ortalama } \\
\text { siklus uzunluğu }\end{array}$ & 0,052 & 0,032 & 0,086 & 1,652 & 0,099 & & & \\
\hline & $\begin{array}{l}\text { Menstruasyon } \\
\text { uzunluğu }\end{array}$ & $-0,474$ & 0,182 & $\begin{array}{c}- \\
0,136\end{array}$ & $-2,605$ & $0,010^{*}$ & & & \\
\hline & $\begin{array}{l}\text { Kullanılan ped } \\
\text { sayısı }\end{array}$ & 0,661 & 0,139 & 0,248 & 4,757 & $0,000 *$ & & & \\
\hline $\begin{array}{c}\text { Bağımlı } \\
\text { Değişken }\end{array}$ & $\begin{array}{l}\text { Bağımsız } \\
\text { Değişken }\end{array}$ & B & SH & Beta & $\mathbf{t}$ & $\mathbf{p}$ & $\mathbf{F}$ & $\begin{array}{l}\text { Model } \\
\text { (p) }\end{array}$ & $\begin{array}{c}\text { Adjusted } \\
\text { R2 } \\
\end{array}$ \\
\hline \multirow{4}{*}{$\begin{array}{l}\text { Genital } \\
\text { Hijyen } \\
\text { Davranışları } \\
\text { Ölçeği }\end{array}$} & Sabit & 90,851 & 3,601 & - & 25,231 & 0,000 & \multirow[t]{4}{*}{7,307} & \multirow[t]{4}{*}{$0,000^{*}$} & \multirow[t]{4}{*}{$\mathbf{0 , 0 5 2}$} \\
\hline & $\begin{array}{l}\text { Ortalama } \\
\text { siklus } \\
\text { uzunluğu }\end{array}$ & 0,112 & 0,080 & 0,074 & 1,406 & 0,161 & & & \\
\hline & $\begin{array}{l}\text { Menstruasyon } \\
\text { uzunluğu }\end{array}$ & $-0,892$ & 0,459 & $0,-$ & $-1,946$ & 0,053 & & & \\
\hline & $\begin{array}{l}\text { Kullanılan ped } \\
\text { sayısı }\end{array}$ & 1,510 & 0,350 & 0,227 & 4,310 & 0,000 & & & \\
\hline $\begin{array}{c}\text { Bağımlı } \\
\text { Değişken }\end{array}$ & $\begin{array}{l}\text { Bağımsız } \\
\text { Değişken }\end{array}$ & $\mathbf{B}$ & SH & Beta & $\mathbf{t}$ & $\mathbf{p}$ & $\mathbf{F}$ & $\begin{array}{l}\text { Model } \\
\text { (p) }\end{array}$ & $\begin{array}{c}\text { Adjusted } \\
\text { R2 }\end{array}$ \\
\hline \multirow{4}{*}{$\begin{array}{l}\text { Anormal } \\
\text { Bulgu } \\
\text { Farkındalığı }\end{array}$} & Sabit & 10,077 & 0,865 & - & 11,650 & 0,000 & \multirow[t]{4}{*}{3,448} & \multirow[t]{4}{*}{$0,017^{*}$} & \multirow[t]{4}{*}{$\mathbf{0 , 0 2 1}$} \\
\hline & $\begin{array}{l}\text { Ortalama } \\
\text { siklus } \\
\text { uzunluğu }\end{array}$ & 0,034 & 0,019 & 0,094 & 1,763 & 0,079 & & & \\
\hline & $\begin{array}{l}\text { Menstruasyon } \\
\text { uzunluğu }\end{array}$ & $-0,066$ & 0,110 & $\begin{array}{c}- \\
0,032\end{array}$ & $-0,599$ & 0,549 & & & \\
\hline & $\begin{array}{l}\text { Kullanılan ped } \\
\text { sayısı }\end{array}$ & 0,236 & 0,084 & 0,150 & 2,809 & $0,005^{*}$ & & & \\
\hline
\end{tabular}




\section{TARTIŞMA}

Menstruasyon kavramı, kadınlar arasında en çok paylaşılan deneyimlerden biri olmasına rağmen sosyal ve kültürel özelliklere bağlı olarak her toplumda farklı bir şekilde algılanmaktadır.2,3 Çalışmamızda öğrencilerin MTÖ toplam puan ortalaması 93,31 $\pm 10,27$ olarak bulunmuştur. 584 hemşirelik öğrencisi ile yapılan bir çalışmada, MTÖ toplam puan ortalamasi 96,33 $\pm 8,98$ olarak bulunmuştur. ${ }^{18}$ Çalışmamıza katılan öğrencilerin menstruasyon tutumunun olumlu olduğu söylenebilir. Garg ve ark., menstruasyon ile ilgili eğitimin menarştan çok önce başlayan ve sonra da devam eden uzun vadeli, sürekli bir süreç olarak düşünülmesini önermektedirler. ${ }^{19}$ Eğitim hayat1 boyunca menstruasyonun fizyolojik, psikolojik ve çevresel özelliklerine ilişkin aldıkları bilgiler doğrultusunda hemşirelik öğrencilerinin olumlu bir tutum sergilemesi beklenen bir sonuçtur. Çalışmamızda öğrencilerin menstruasyonu doğal bir olgu olarak görmesinin genital hijyen ve adet hijyeni davranışlarını olumlu etkilediği saptanmıştır. Gana'da yapılan çalışmada, menstruasyon hakkında bilgi düzeyi arttıkça, menstruasyon hijyeni ile ilgili olumlu uygulamaların $\operatorname{arttı̆̆}_{1}$ saptanmıştır. ${ }^{20}$ Menstruasyonun doğal bir olgu olarak kabul edilmesi ve okullarda verilen eğitimin bu yönde şekillendirilmesi, menstruasyonla ilgili ev, okul ve iş ortamında karşılaşılan güçlüklerle baş edilmesinde ve enfeksiyonların önlenmesinde bir çözüm yolu olarak düşünülebilir. Araştırmaya katılan

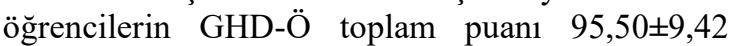
olarak bulunmuştur. 173 hemşirelik öğrencisi ile yapılan diğer bir çalışmada, GHD-Ö toplam puanı $87,60 \pm 8,97$ olarak belirlenmiştir. ${ }^{21}$ Sağlık bilimleri alanında okuyan öğrencilerin bireysel hijyen davranışlarının olumlu olması beklenen bir durumdur. Çalışmamızda da literatür ile uyumlu olarak öğrencilerin genital hijyen davranışının olumlu olduğu saptanmıştır.

Çalışmamıza katılan öğrencilerin \%63,8'i yurt ortamında barınmaktadır. Öğrencilerin GHD-Ö genel hijyen alışkanlıkları alt boyutu toplam puanı $49,36 \pm 5,01$ olarak ortalama puanın üstünde bulunmuştur.Üniversitede yurtta kalan k1z öğrenciler ile yapılan bir çalışmada, herhangi bir genital enfeksiyon şikâyeti nedeniyle yardım arama davranışında bulunmayan öğrencilerin oranı \%60,7 olarak saptanmıştır. ${ }^{22}$ Çalışmamızda hemşirelik öğrencilerinin genel hijyen alışkanlıkları iyi düzeyde olmasına rağmen istendik düzeyde değildir. Hemşirelerin öğrencilikten başlayarak profesyonel meslek yaşamı boyunca toplum sağlığının korunması ve geliştirilmesinde önemli rolleri bulunmaktadır. Hemşire öğrencilerin yaşadıkları ortamlarda akranlarını etkileyebilme ve eğitebilmeleri için istendik düzeyde bilgi ve alışkanlık düzeyine sahip olması gereklidir. Öğrencilerin sosyodemografik özelliklerinden gelir durumu denk ve yüksek olanların GHD-Ö toplam ve adet hijyeni alt boyut puan ortalamaları daha yüksek bulunmuştur. Bireysel hijyen durumunun sosyoekonomik koşullardan etkilendiği göz önüne alındığında öğrencilerin hijyen ürünlerine ulaşımının kolaylaştırılmasının genital hijyen davranışlarını olumlu etkileyebileceği düşünülmektedir. Menstrual sağlık menstrual ürünlere ulaşma, hijyenik menstrual uygulamaları sürdürme ve doktora gittiğinde rahat hissetme gibi durumları içermektedir. ${ }^{23}$ Kore'de 383 üniversite öğrencisi ile yapılan bir çalışmada, öğrencilerin genitoüriner enfeksiyonlarla ilişkili uygun olmayan adet hijyeni uygulamaları olduğu saptanmıştır. ${ }^{24}$ Çalışmamızda öğrencilerin GHD-Ö adet hijyeni alt boyut puan ortalaması 34,45 $\pm 3,92$ olarak bulunmuştur. Öğrencilerin hijyenik menstrual uygulamaları yüksek oranda gerçekleştirdiği söylenebilir. Çalışmamızda kullanılan ped sayısının genital hijyen alışkanlıkları ve adet hijyeni üzerinde etkili olduğu saptanmıştır. Yeterli adet hijyenini sürdürmek için eğitim sağlamak, öğrencilerin ekonomik durumuna uygun ve alternatif adet hijyeni ürünleri hakkında farkındalık yaratmak, öğrencilerin optimal bir menstrual sağlık düzeyine ulaşmalarını kolaylaştırabilir.

\section{SONUÇ}

Çalışmamızda öğrencilerin MTÖ toplam puan ortalaması 93,31 $\pm 10,27$, GHD-Ö toplam puanı

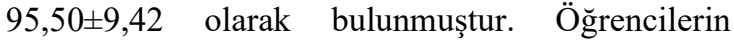
menstruasyon tutumu ve genital hijyen davranışları olumludur. Çalışmamızda öğrencilerin menstruasyonu doğal bir olgu olarak görmesinin menstrual hijyen davranışlarını olumlu etkilediği bulunmuştur. Bu doğrultuda ilk deneyimden itibaren menstruasyonla ilgili kazandırılacak olumlu tutumlar, kadınların tüm hayat dönemlerinde genel sağlık durumunu olumlu yönde etkileyecektir. Menstruasyona ilişkin olumlu bir tutum oluşturabilmek için kuşaklar arasındaki eğilim, medyanın etkisi ve tüm yaş gruplarında bilgi düzeyi gibi faktörlerin ayrı çalışmalarla değerlendirilmesi önerilebilir.Menstrual sağlık içinde hijyenik ürünlere ulaşma önemli bir faktördür. Çalışmamıza katılan öğrencilerin \%63.8'inin yurt ortamında barındığ1 belirlenmiştir. Öğrencilerin hijyen ürünlerine ulaşımının kolaylaştırılması veya ücretsiz temininin üniversitelerce sağlanmasının menstrual sağlık ve genital hijyen düzeyinin arttırılmasında kolaylaştırıcı olacağı düşünülmektedir.

\section{KAYNAKLAR}

1. Can HÖ. Menstrual Siklus Bozuklukları. Şirin A, Kavlak O, editorler. Kadın Sağlığı. Nobel Tıp Kitabevleri; 2015. p. 94.

2. Litman J. Menstruation Stigma Must Stop. Period. The Public Health Advocate. 2018. Available from: 
https://pha.berkeley.edu/2018/06/05/menstruationstigma-must-stop-period/ [erişim tarihi: 14.04.2021]

3. Ali TS, Rizvi SN. Menstrual knowledge and practices of female adolescents in urban Karachi, Pakistan. J Adolesc. 2010 Aug;33(4):531-41.

4. Whelan EM. Attitudes toward Menstruation. Stud Fam Plann. 1975;6.

5. Şenol V, Gündüz E, Öztürk A. Kayseri İlinde Adölesan Kızların Menarş ve Menstürasyon Konusunda Bilgi Tutum ve Davranışları.Turkiye Klinikleri Journal of Gynecology and Obstetrics, 2010;20(2):77-83

6. Sánchez-Borrego R, García-Calvo C. Spanish women's attitudes towards menstruation and use of a continuous, daily use hormonal combined contraceptive regimen. Contraception. 2008 Feb;77(2):114-7.

7. Çevirme AS, Çevirme H, Karaoğlu L, Uğurlu N, Korkmaz Y. The perception of menarche and menstruation among Turkish married women: Attitudes, experiences, and behaviors. Soc Behav Pers. 2010;38(3):381-94.

8. Akbaş T, Sanberk İ.İlk Menstrüasyon ve Ejakülasyon Deneyimi: Hazirlik Ön Yaşantilar ve Ön Bilgilerin Cinsel Tutum ve Davranışlarla İlişkisinin İncelenmesi. Çukurova Üniversitesi Sos Bilim Enstitüsü Derg. 2012;21(3):323-38.

9. Uskul AK. Women's menarche stories from a multicultural sample. Soc Sci Med. 2004 Aug;59(4):667-79.

10. Whisnant L, Zegans L. A study of attitudes toward menarche in white middle-class American adolescent girls. Am J Psychiatry. 1975;132(8):80914.

11. Hennegan Id J, Shannon AK, Id JR, Schwab KJ, Melendez-Torres GJ. Women's and girls' experiences of menstruation in low- and middleincome countries: A systematic review and qualitative metasynthesis. 2019; May16;16(5):e1002803

12. Torondel B, Sinha S, Mohanty JR, Swain T, Sahoo P, Panda B, et al. Association between unhygienic menstrual management practices and prevalence of lower reproductive tract infections: a hospital-based cross-sectional study in Odisha, India. BMC Infect Dis. 2018 Sep;18(1):473.

13. Ünsal A. Üniversitede Okuyan Kız Öğrencilerin Genital Hijyen Davranışları. Fırat Sağlık Hizmetleri Dergisi.2010;5(13):80-93
14. Topuz Ş, Büyükkayacı Duman N, Güneş A. Sağlık Bilimleri Fakültesi Birinci Sınıftaki Kız Öğrencilerin Genital Hijyen Uygulamaları. Turkish J Clin Lab. 2015;6(3). 79-93

15. Güneri SE, Şen S, Öğrenci Hemşirelerin Genital Hijyen Uygulamaları ve Farkındalıkları.Manisa Celal Bayar Üniversitesi Sağlık Bilimleri Enstitüsü Dergisi.2020;7(2): 96 -101

16. Karahan N. Genital Hijyen Davranışları Ölçeğinin Geliştirilmesi: Geçerlik Güvenirlik Çalışması. İstanbul Med J. 2017;18(3):157-62.

17. Kulakaç Ö, Öncel S, Fırat Mz, Akcan A. Menstruasyon Tutum Ölçeği: Geçerlik ve Güvenirlik Çalışması. J Clin Obstet Gynecol 2008;18(6):347-56.

18. Yılmaz B, Şahin N. Bir hemşirelik fakültesi öğrencilerinin primer dismenore sıklığ 1 ve menstrual tutumları. Mersin Üniversitesi Sağlık Bilim Derg. 2019;12(3):426-38.

19. Garg S, Sharma N, Sahay R. Socio-cultural aspects of menstruation in an urban slum in Delhi, India. Reprod Health Matters 2001;9(17):16-25.

20. Ameade EPK, Garti HA. Relationship between Female University Students' Knowledge on Menstruation and Their Menstrual Hygiene Practices: A Study in Tamale, Ghana. Adv Prev Med ;2016:1-10.

21. Bulut A, Yigitbaş Ç,Çelik G. Hemşirelik Öğrencilerinin Perspektifinden Genital Hijyen Davranışları. Ankara Eğitim ve Araştırma Hastan Tip Derg. 2019;52(3):227-32.

22. Yüksel P, Gülhan H, Şirin F, Uygun H, Bilgiç D. Üniversitede Yurtta Kalan Kız Ögrencilerin Genital Hijyen Davranışları ve Sağlık Sonuçları. Acibadem Univ Saglik Bilim Derg 2020;3(3):478 - 485.

23. Mostafa I. The Real Period Stain: Menstrual Stigma and Its Pressures in South Asia. 2019 Available from: https://digitalcommons.augustana.edu/celebrationof learning/2019/presentations/3[erişim tarihi:14.04.2021]

24. Kim KM, Choi JS. Female university students' menstrual-hygiene management and factors associated with genitourinary-tract infections in Korea. Women Heal. 2020 May ;60(5):559-69. 